\title{
Comprehensive review of imaging of intracranial aneurysms and angiographically negative subarachnoid hemorrhage
}

\author{
*Brian M. Howard, MD, ${ }^{1,2}$ Ranliang Hu, MD, ${ }^{2}$ Jack W. Barrow, BS, ${ }^{3}$ and Daniel L. Barrow, MD' \\ 1Department of Neurosurgery, and 2Department of Radiology and Imaging Sciences, Division of Interventional Neuroradiology, \\ Emory University School of Medicine, Atlanta; and ${ }^{3}$ Mercer University School of Medicine, Savannah, Georgia
}

\begin{abstract}
Intracranial aneurysms confer the risk of subarachnoid hemorrhage (SAH), a potentially devastating condition, though most aneurysms will remain asymptomatic for the lifetime of the patient. Imaging is critical to all stages of patient care for those who harbor an unruptured intracranial aneurysm (UIA), including to establish the diagnosis, to determine therapeutic options, to undertake surveillance in patients who elect not to undergo treatment or whose aneurysm(s) portends such a low risk that treatment is not indicated, and to perform follow-up after treatment. Neuroimaging is equally as important in patients who suffer an SAH. DSA remains the reference standard for imaging of intracranial aneurysms due to its high spatial and temporal resolution. As noninvasive imaging technology, such as CTA and MRA, improves, the diagnostic accuracy of such tests continues to increasingly approximate that of DSA. In cases of angiographically negative $\mathrm{SAH}$, imaging protocols are necessary not only for diagnosis but also to search for an initially occult vascular lesion, such as a thrombosed, ruptured aneurysm that might be detected in a delayed fashion. Given the crucial role of neuroimaging in all aspects of care for patients with UIAs and SAH, it is incumbent on those who care for these patients, including cerebrovascular neurosurgeons, interventional neurologists and neuroradiologists, and diagnostic radiologists and neurointensivists, to understand the role of imaging in this disease and how individual members of the multispecialty team use imaging to ensure best practices to deliver cutting-edge care to these often complex cases. This review expounds on the role of imaging in the management of UIAs and ruptured intracranial aneurysms and in the workup of angiographically negative subarachnoid hemorrhage.
\end{abstract}

https://thejns.org/doi/abs/10.3171/2019.9.FOCUS19653

KEYWORDS intracranial aneurysm; imaging; angiography; interventional neuroradiology; subarachnoid hemorrhage

I NTRACRANIAL aneurysms are relatively common with a prevalence of approximately $4 \% .{ }^{44}$ Most aneurysms are small, asymptomatic, and unlikely to bleed. Unruptured intracranial aneurysms (UIAs) are increasingly common with age, with the highest incidence in those aged between 75 and 84 years (61.6 per 100,000 persons). ${ }^{3}$ Unfortunately, our knowledge of the natural history of UIAs is incomplete, and we cannot reliably predict which aneurysms will remain silent and which will rupture and result in subarachnoid hemorrhage (SAH). This makes clinical decision-making a challenge and imaging important in the diagnosis and management of aneurysms.

$\mathrm{SAH}$ is a relatively uncommon but devastating type of hemorrhagic stroke. According to the World Health Organization, the incidence of SAH varies significantly across the globe, from 2.0 to 22.5 per $100,000 .{ }^{16}$ Approximately 30,000 spontaneous SAHs occur per year in the United States. ${ }^{16}$ Although morbidity and mortality resulting from $\mathrm{SAH}$ have improved over the past several decades, allcause mortality still hovers around 30\%-40\%, and survivors are often plagued by chronic headaches, sleep disorders, and neurocognitive and psychiatric problems that adversely affect quality of life. .16,42 $^{1}$

SAH classically presents as an acute onset of the worst headache of a person's life and is often associated with nausea and vomiting, nuchal rigidity, loss of consciousness, and seizure; upwards of $15 \%$ of patients die before reaching medical services. ${ }^{5,16,40}$ A smaller "sentinel bleed" may occur within the few weeks prior to a large SAH and typically manifests as symptoms milder than the more ex-

ABBREVIATIONS ANSAH = angiographically negative SAH; DE-CTA = dual-energy CTA; ICA = internal carotid artery; ICGVA = indocyanine green video angiography; $I O A$ = intraoperative angiography; $M C A=$ middle cerebral artery; $\mathrm{SAH}$ = subarachnoid hemorrhage; $\mathrm{TOF}$ = time-of-flight; TR CE = time-resolved contrast-enhanced; UIA = unruptured intracranial aneurysm.

SUBMITTED August 1, 2019. ACCEPTED September 20, 2019

INCLUDE WHEN CITING DOI: 10.3171/2019.9.FOCUS19653.

* B.M.H. and R.H. contributed equally to this work. 
tensive SAH. ${ }^{35}$ As recently as the mid-1980s, the initial misdiagnosis rate for SAH was upwards of $65 \%$, but more recent studies show the rate hovers around $10 \% .{ }^{29,31,59}$ If the source of SAH is an aneurysm, the rehemorrhage rate without treatment is approximately $50 \%$ over the ensuing 6 months, the majority of repeat hemorrhages occurring within the first $24-48$ hours of initial rupture. ${ }^{24,39}$ Given the prevalence of misdiagnosis and the potential consequences of missing a potentially treatable cause of SAH, prompt and comprehensive imaging is of utmost importance if clinical suspicion for SAH is high.

In this review, we summarize the spectrum of imaging related to the diagnosis and treatment of intracranial aneurysms and angiographically negative SAH (ANSAH). Imaging is indispensable in all facets of the care of patients with intracranial aneurysms, and, as imaging techniques become increasingly advanced, a comprehensive understanding of the benefits and limitations of various radiological studies is required to most efficiently and comprehensively care for patients with UIAs and SAH.

\section{UIAs: Who Is Imaged and Why?}

As neuroimaging is increasingly used to evaluate a wide range of symptoms, more incidental aneurysms are being discovered and referred for neurosurgical evaluation. A recent study found incidental UIAs in $2.3 \%$ of 5800 healthy participants undergoing brain MRI, the second most prevalent incidental finding after meningiomas. ${ }^{8}$ The vast majority of these were small $(<7 \mathrm{~mm})$ and remained stable, while 1 of $16(6.3 \%)$ aneurysms $\geq 7 \mathrm{~mm}$ ruptured during the follow-up period (5 years). While previous prospective observation studies ${ }^{38,67}$ also support that anterior circulation aneurysms smaller than $7 \mathrm{~mm}$ carry low risk of rupture, recent reports describe an increasing incidence of small and tiny aneurysms as a proportion of total ruptured aneurysms. ${ }^{6}$

The imaging studies used most commonly to diagnose and monitor aneurysms are CTA, MRA, and DSA. Noninvasive angiographic imaging modalities, such as CTA and MRA, have greatly improved the detection and evaluation of cerebral aneurysms, but false-positive findings occur due to technical limitation with regard to spatial resolution and imaging artifact, as well as anatomical reasons such as vessel tortuosity and overlapping venous structures. Overdiagnosis of incidental small aneurysms can lead to unwarranted anxiety, unnecessary clinical referrals, and additional imaging studies. As imaging utilization increases, many "possible 1-2 mm aneurysms" are reported in patients in whom no intervention would be considered. In many of these patients, no further imaging or follow-up is necessary, as the risk of SAH is far less than the risk carried by an intervention. For younger patients who select against intervention, serial imaging is necessary to identify a change in the aneurysm that may portend a more sinister future and warrant a reconsideration of intervention. This is typically accomplished with either CTA or MRA performed annually at first and at more protracted intervals if the aneurysm has remained stable for a long period, but an optimal follow-up strategy has not yet been defined.
Treatment recommendations should be individualized and take into consideration both patient factors and aneurysm features. Imaging is vitally important to determine the size and location of the aneurysm and its relationship to surrounding anatomy. As size and location are the most significant predictors of SAH risk, accurate measurement of the aneurysm(s) is imperative. Not only does SAH risk vary with location within the anterior versus posterior circulation, but determining if an aneurysm is in fact intracranial as the carotid artery transitions from the cavernous to clinoidal and supraclinoid segments is immensely important to counsel patients regarding the risk of harboring such an aneurysm. This determination is not straightforward as the distal dural ring separating the intradural from the extradural carotid artery is not well delineated on imaging. Imaging surrogates, such as the ophthalmic artery origin seen on DSA or the optic strut seen on CTA, are variable and inconsistently visualized. ${ }^{27}$ Raising more uncertainty, UIAs of the clinoidal segment of the internal carotid artery (ICA) can protrude medially through a potential space formed by a redundant distal dural ring ("carotid cave") and cause SAH. High-resolution MRI sequences have the potential to directly visualize the dural folds to determine the intra- versus extradural location of transitional aneurysms, but these are not yet performed routinely. ${ }^{55}$

Aneurysm geometry is associated with the likelihood of $\mathrm{SAH}$, as aneurysms with irregular protrusion, or "daughter" sacs, rupture at higher rates. Features such as partial thrombosis or calcification are associated with larger aneurysms, which in turn confer a higher risk of rupture; whether calcification or thrombosis is independently associated with rupture is unproved. ${ }^{38}$ Advanced MRA techniques and vessel wall imaging have theoretical roles in aneurysm risk assessment, but they remain investigational. ${ }^{17,25}$

Imaging is important in determining which therapeutic options are optimal for individual aneurysms. Although DSA remains the gold standard for imaging UIAs, CTA and MRA are more often being used to make surgical decisions without DSA due to their greater availability and noninvasiveness. CTA has the additional ability of delineating the surrounding nonvascular anatomy and depicting the presence of calcifications, which can alter the surgical approach. A potential risk of noninvasive imaging is missing a small aneurysm that could potentially be treated at the time of surgery if its presence were known. ${ }^{9}$ CTA and MRA may be adequate to determine if an endovascular option exists for a particular aneurysm, but ultimately, DSA is typically performed before deciding to proceed with endovascular treatment, particularly if the patient requires antiplatelet therapy prior to treatment. In many cases, particularly for ruptured aneurysms, the diagnostic angiographic study and endovascular therapy are performed at the same sitting. Our algorithm for the imaging workup of incidentally discovered and symptomatic UIAs is demonstrated in Figs. 1 and 2.

\section{Initial Workup and Radiographic Evaluation of SAH}

Neuroradiological evaluation of patients with suspected SAH requires imaging to establish both the diagnosis and 


\section{Aneurysm Screening in Asymptomatic Patients}

- $\geq 2$ family members with intracranial aneurysms (IA), or SAH (Class I, Level of Evidence [LoE] B)

- Autosomal dominant Polycystic Kidney Disease (Class I, LoE B)

- Coarctation of the Aorta (Class Ila, LoE B)

- Microcephalic Osteodysplastic Primordial Dwarfism (Class Ila, LoE B)

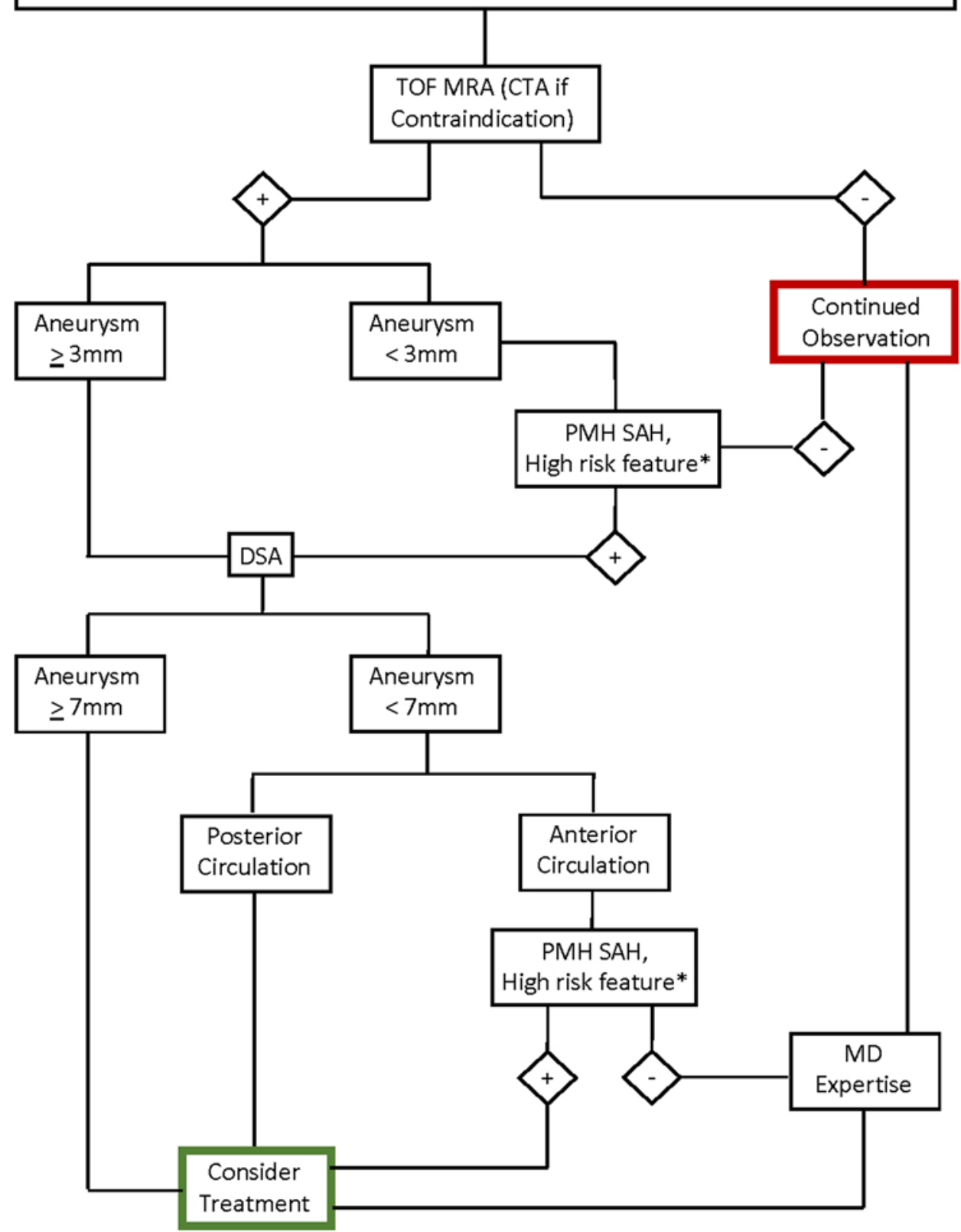

FIG. 1. Flowchart depicting our approach to the workup of asymptomatic UIAs. ${ }^{58}$ * High-risk features include family history of aneurysmal SAH, smoking, stimulant drug use, and morphological features of the aneurysm, such as irregular shape, daughter sacs, or partial thrombosis. $\mathrm{MD}=$ medical doctor; $\mathrm{PMH}=$ past medical history.

the source. Noncontrast CT is the initial imaging study used to document SAH. As early-generation CT failed to reveal SAH in a substantial percentage of patients, it became dogma to perform a lumbar puncture to rule out $\mathrm{SAH}$ through the detection of xanthochromia by CSF spectrophotometry. ${ }^{20}$ The role of lumbar puncture in the workup of SAH has diminished, as the diagnostic accuracy of modern, multislice CT has improved in combination with potential complications, patient preference, and reduced specificity due to traumatic taps, which are esti- 


\section{Aneurysm Screening in Symptomatic Patients}

- Bystander aneurysm in the setting of subarachnoid hemorrhage

- Headache, cranial nerve palsy, seizure, mass effect from the aneurysm

- Incidental aneurysm found on work-up, headache not associated with the aneurysm, neurological signs/symptoms from non-aneurysmal intracranial hemorrhage, cerebral ischemia, CNS degenerative disease, brain tumors, etc

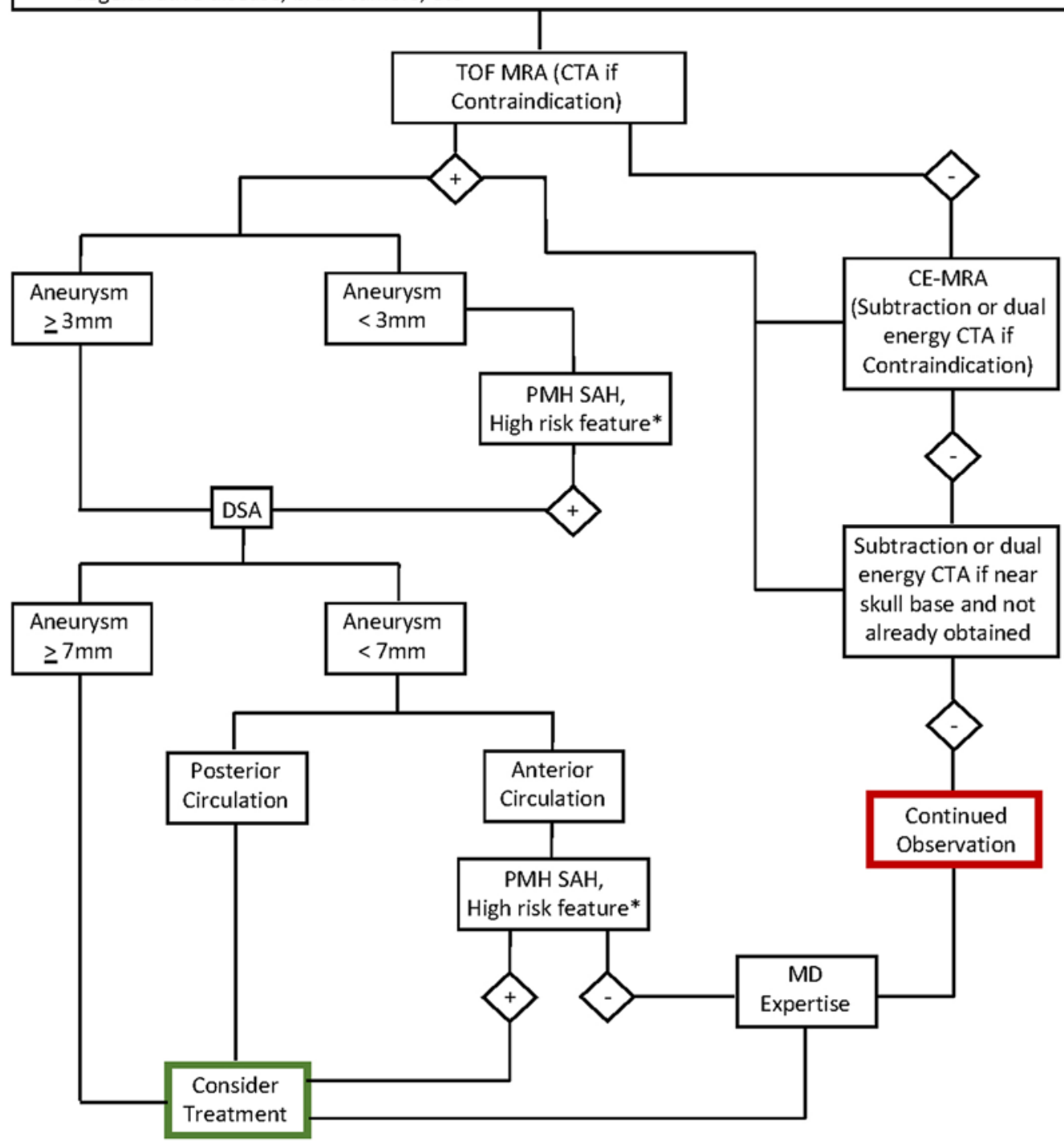

FIG. 2. Flowchart depicting our approach to the workup of symptomatic UIAs. ${ }^{58}$ * High-risk features include family history of aneurysmal SAH, smoking, stimulant drug use, and morphological features of the aneurysm, such as irregular shape, daughter sacs, or partial thrombosis.

mated to occur in about 1 of every 6 lumbar punctures..$^{50}$ Data from across the recent literature demonstrate that the sensitivity of CT to detect SAH within 6 hours of symptom onset approaches 100\%. Beyond 6 hours of symptom onset, the pooled sensitivity of CT drops to $89 \% .{ }^{4}$ While guidelines still recommend lumbar puncture after a negative result on CT if clinical suspicion for SAH is high, these data imply that lumbar puncture after a negative CT to "rule out" SAH no longer seems rational for the large majority of patients. ${ }^{12}$
MRI has a limited role in the detection of SAH. A FLAIR sequence can depict subarachnoid blood as regions of non-CSF suppression, but it is highly nonspecific and can be caused by various technical factors, hyperoxygenation, anesthetic medication, and other meningeal disease processes. MRI sequences optimized to detect the paramagnetic effect of blood, such as gradient-recalled echo and susceptibility weighted imaging, are highly sensitive for acute, subacute, and chronic blood products, but they cannot detect hyperacute hemorrhage when it is still 
in the oxyhemoglobin stage. Often, the value of MRI in the setting of SAH is in rare circumstances or in the detection of nonvascular etiologies.

\section{Imaging Modalities DSA}

The gold standard for the diagnosis of both UIAs and ruptured intracranial aneurysms is DSA because it remains the test with the highest spatial and temporal resolution. The diagnostic accuracy of DSA is enhanced by 3D rotational angiography, which images the cerebral vasculature from all angles. DSA is relatively expensive, is invasive, and historically is associated with a $0.5 \%$ incidence of permanent neurological complications. ${ }^{32,60,61}$ More recent studies, however, have demonstrated that modern catheter cerebral angiography performed by trained neurointerventionalists is associated with complication rates of $0.04 \%-$ $0.30 \%$, even in highly complex patient populations. ${ }^{15,23}$

DSA provides the most accurate information about not only aneurysm geometry, including size and shape of the fundus, but also the diameter of the orifice into the aneurysm, the percentage of the circumference of the parent vessel that is involved, and the presence of branch vessels that arise from the neck or fundus that may be put at risk during treatment. These data are taken together to determine whether endovascular or surgical management of the aneurysm is most appropriate. However, DSA is poor at identifying intrasaccular thrombus and calcification, which may influence clinical decision-making, as both intrasaccular thrombus and calcification of the aneurysm neck may significantly increase the difficulty of microsurgical clipping and increase the risk of stroke.

\section{CTA}

CTA was introduced in the 1980s and, as technology has improved, has compared favorably with DSA in terms of diagnostic accuracy. The advantages of CTA over DSA are its relatively low cost, speed of acquisition, and wider availability at smaller hospitals. Various studies and metaanalyses have shown that CTA nearly reproduces the detection capability of DSA but not completely, and less so for smaller aneurysms and in certain locations. Overall, large series and meta-analyses have demonstrated pooled sensitivity and specificity approaching or better than $90 \%$ for CTA in the detection of intracranial aneurysms compared with DSA. ${ }^{13,36,65}$ White et al., ${ }^{65}$ in a study of 677 patients, showed that, while the sensitivity for detection of aneurysms less than $3 \mathrm{~mm}$ in maximal diameter was $61 \%$, the sensitivity for aneurysms larger than $3 \mathrm{~mm}$ was $96 \%$. A more recent meta-analysis, including patients evaluated using modern CTA technology, yielded a sensitivity and specificity for intracranial aneurysm detection over $97 \% .^{36}$ In contrast, a recent prospective study showed CTA to have false-positive and false-negative rates of $21 \%$ and $22 \%$, respectively, with the anterior communicating artery and basilar apex with the highest rate of false positives. ${ }^{43}$ False negatives most frequently occurred at the cavernous portion of the ICA and the middle cerebral artery (MCA), and the majority of undiagnosed aneurysms on CTA were smaller than $5 \mathrm{~mm} \cdot{ }^{43}$
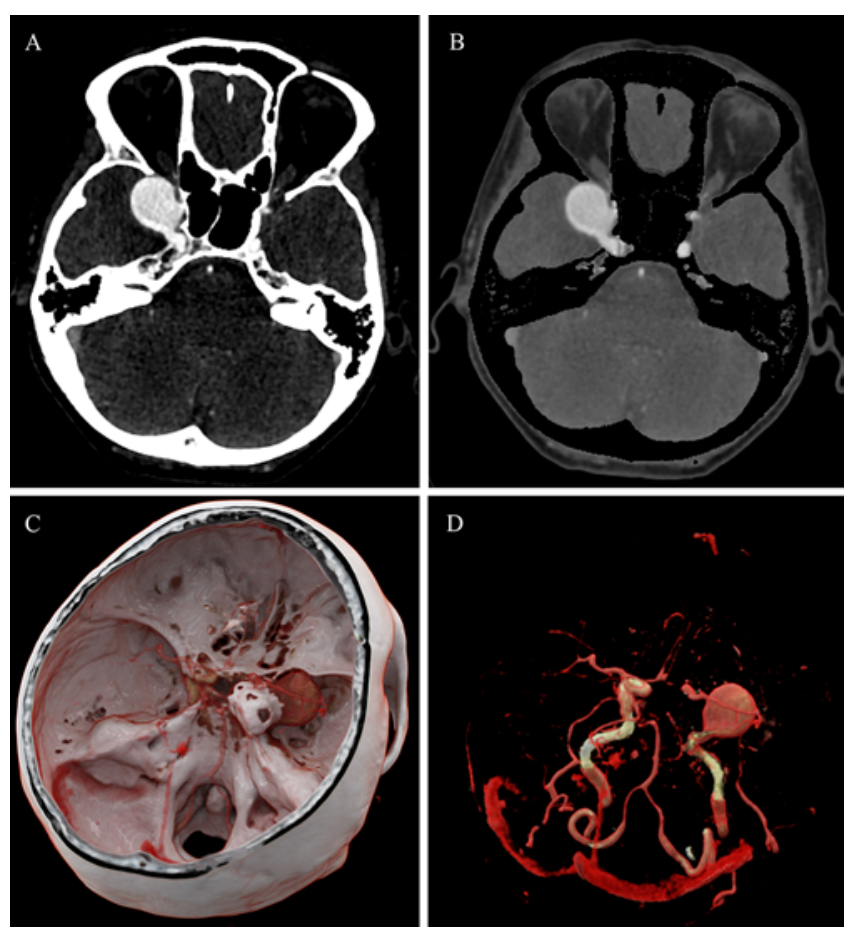

FIG. 3. A: DE-CTA image demonstrating a large right cavernous ICA aneurysm. B: Bone-subtraction CTA facilitates 3D depiction of the aneurysm by removing overlapping bone. $\mathrm{C}$ and $\mathrm{D}$ : $\mathrm{A}$ cinematic $3 \mathrm{D}$ rendering can be generated with realistic color and lighting to highlight the calcified portion of the aneurysm and adjacent bony anatomy $(C)$, while bone subtraction can reveal the aneurysm in its entirety (D).

Recently, dual-energy CTA (DE-CTA) has been shown to be useful in the evaluation of aneurysms ${ }^{70}$ (Fig. 3). DECTA involves simultaneous or near-simultaneous acquisition of two sets of CT data using different energy spectra, enabling the differentiation of materials with similar Hounsfield units (e.g., blood, calcium, and iodine). Information from the higher-energy spectra can be used to reduce beam-hardening artifact, and information from the lower-energy spectra can be used to enhance CTA quality at lower contrast doses. In addition, DE-CTA from various vendors now offers skull subtraction based on the material-specific properties of bone, facilitating 3D reconstruction of the intracranial vasculature and improved visualization of aneurysms at the skull base. Feng et al. ${ }^{21}$ recently showed that DE-CTA yielded a sensitivity and specificity of $95 \%$ and $100 \%$, respectively, with a $60 \%$ reduction in average radiation exposure compared to DSA.

CTA is gradually replacing DSA in many centers for the initial evaluation of SAH. In a large meta-analysis, including 50 studies, evaluating CTA as the primary diagnostic imaging study in patients with $\mathrm{SAH}$, the pooled sensitivity and specificity were $98 \%$ and $100 \%$, respectively. ${ }^{64}$ The analysis included 4097 patients with sensitivities ranging from $86 \%$ to $100 \%$ and specificity ranging from $50 \%$ to $100 \%$. A ruptured aneurysm was missed in 71 cases on CTA. The location of the false negatives was specified for 53 aneurysms (most commonly the ICA $[\mathrm{n}=27\{51 \%\}]$, posterior inferior cerebellar artery $[\mathrm{n}=7$ 
$\{13 \%\}]$, and MCA [n = $5\{9 \%\}])$. The size was provided in 40 cases, and 36 aneurysms were smaller than $5 \mathrm{~mm}$, while 4 were between 5 and $10 \mathrm{~mm}$. Interestingly, 19 of the missed aneurysms were detected retrospectively, emphasizing the importance of double reading the studies and of the experience of the radiologist. ${ }^{66}$ The specificity was comparable between 4- and 16- or 64-row detector scanners; sensitivity was improved on 16- and 64-row detector scanners.

In the setting of SAH, DSA remains the preferred method to evaluate for a causative cerebrovascular abnormality. Although some neurosurgeons justify clipping ruptured intracranial aneurysms without DSA by the high sensitivity and specificity of CTA (discussed below), we feel that, unless surgery is required in the case of a life-threatening emergency, patients are better served by the decision to surgically treat a ruptured aneurysm on the basis of both DSA and CTA data. CTA is useful to determine the clot burden within the aneurysm and neck or wall calcification, as well as to determine the relationship of the aneurysm to the bony skull base. However, false-negative CTA results may miss additional bystander aneurysms that can often be clipped during a single craniotomy to eliminate the need for a second procedure. If the patient is determined to be a candidate for endovascular therapy, DSA will be needed either for treatment planning or as part of the therapeutic procedure.

\section{MRA}

Time-of-flight MRA (TOF MRA) is the most commonly used MRA technique to evaluate UIAs and is often performed with 3D reconstructions with maximum intensity projections (also known as MIPs) and volume renderings to provide excellent views of aneurysms. It offers superb resolution without the use of contrast and is being utilized with increased frequency in evaluating UIAs. ${ }^{68}$ Unlike DSA or CTA, TOF MRA relies on the intrinsic magnetic properties of flowing blood to generate signal. Importantly, TOF MRA does not image the vessel lumen but instead depends on the steady inflow of magnetized blood. Thus, images can be compromised by various artifacts, such as saturation from vascular tortuosity, turbulent flow within large aneurysm sacs, and metal artifact. In contrast-enhanced MRA, exogenous gadolinium administered intravenously can be acquired in a single acquisition or as a time-resolved series (TR CE-MRA) to better visualize intracranial vessels when intrinsic signal is insufficient or limited by artifact, though the temporal resolution is lower than DSA (typically on the order of several seconds compared to fractions of a second for DSA). Figure 4 demonstrates the differences between TOF MRA and TR CE-MRA.

A recent systematic review and meta-analysis of MRA in the diagnosis of intracranial aneurysms reported a pooled sensitivity and specificity of $95 \%$ and $89 \%$, respectively. ${ }^{49}$ False-negative and false-positive aneurysms were primarily located at the skull base and MCA. The analysis also revealed important caveats. Freehand, postprocessed 3D reconstructions significantly increased the diagnostic performance as compared to fixed reconstructions in standard planes, and studies performed on a 3-T unit showed
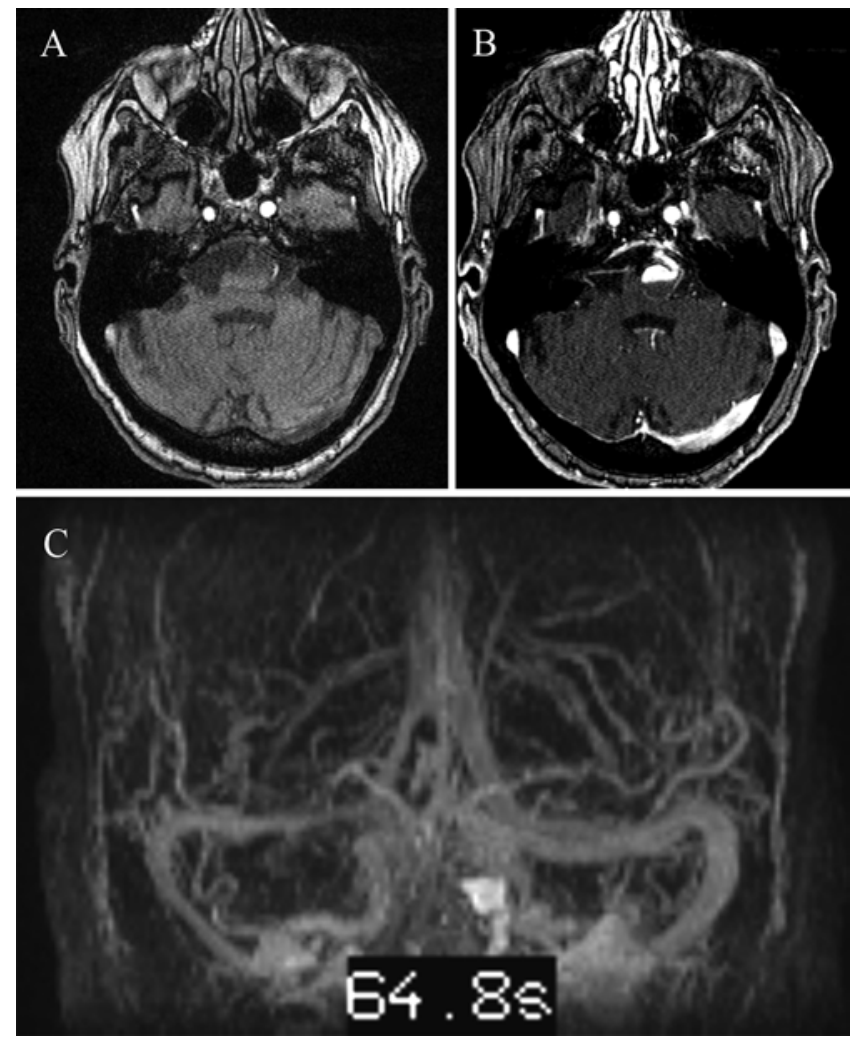

FIG. 4. A: A TOF MRA image of the head failing to demonstrate a large left vertebral artery aneurysm due to the slow and turbulent flow within the aneurysm sac. B: Contrast-enhanced MRA image showing partial thrombosis of the aneurysm. C: Time-resolved MRA image demonstrating delayed filling and stasis of contrast material within the aneurysm sac.

a trend toward higher performance. ${ }^{49}$ Other studies confirm a slight, but not statistically significant, advantage of $3 \mathrm{~T}$ over $1.5 \mathrm{~T}$ in the detection of intracranial aneurysms, while $7 \mathrm{~T}$ remains experimental. ${ }^{30,63}$ Similar to CTA, the diagnostic power of MRA is diminished in the detection of aneurysms $\leq 5 \mathrm{~mm}$ and those at the skull base. ${ }^{49}$

TOF MRA has a number of advantages over CTA and DSA. It can be used in patients who cannot tolerate iodinebased contrast, such as those with allergic reactions or with renal failure. Also, MRA does not expose patients to any ionizing radiation. Although the radiation dose from a single CTA study is small, the cumulative dose may become significant for patients followed for long-term surveillance. Also, nonangiographic MR images, such as T1- and T2weighted images, are often performed along with MRA and are useful for demonstrating intraluminal thrombus and more accurately determining the size of partially thrombosed aneurysms.

These advantages must be weighed against the disadvantages of MRA, which include the need for patients to be screened for MRI compatibility, the lack of universal availability, especially during after-hours, longer acquisition time, the difficulty of performing MRI in critically ill patients, and the relatively higher cost (vs CTA). Although CTA often provides higher resolution and robustness to artifact and can be helpful in the initial workup, we rec- 
Howard et al.
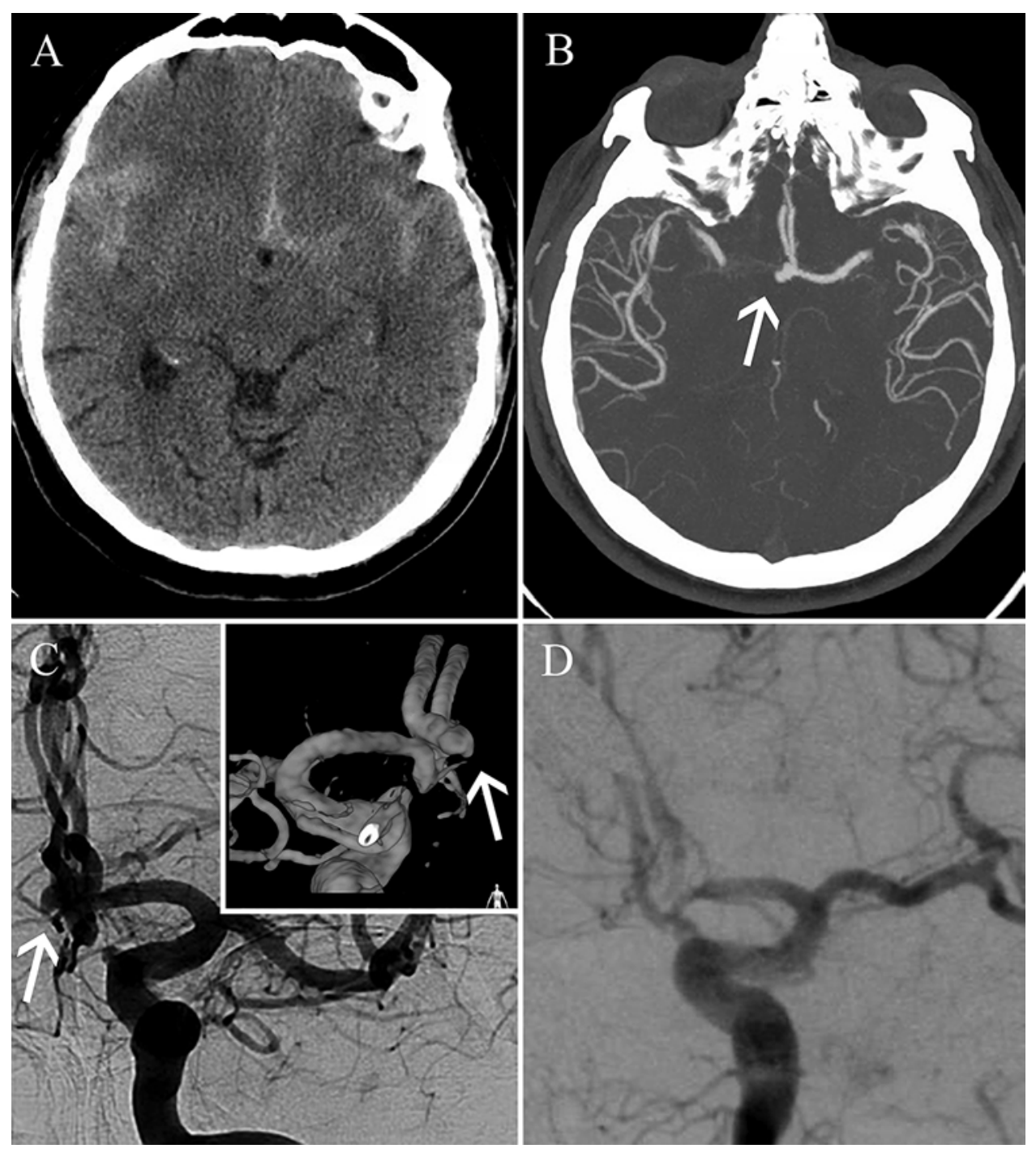

FIG. 5. Imaging examples typical of an SAH patient who underwent clipping. A: CT scan showing diffuse SAH in the sylvian fissures, suprachiasmatic cistern, and interhemispheric fissure. B: CT scan revealing a left $A_{1-2}$ junction anterior cerebral artery (ACA) aneurysm. C: Angiogram revealing a wide-neck left $A_{1-2}$ junction $A C A$ aneurysm. Inset: $3 D$ angiogram showing the wideneck nature of the aneurysm (arrow) involving the transition from the left $A_{1}$ segment to the ipsilateral $A_{2}$ segment (projection from posterior to anterior). D: Intraoperative angiogram demonstrating complete occlusion of the aneurysm and normal filling of the surrounding vasculature.

ommend following patients with MRA, when possible, to eliminate the cumulative dose of radiation and avoid the need for administrating iodinated contrast material. It is prudent to specify on the imaging order the location of the aneurysm and if whole-brain MRA is needed, as routine TOF MRA only includes the circle of Willis in most centers and could potentially not image a more distal aneurysm.

Though commonly used to detect and follow UIAs, MRA is generally not used in the workup of SAH for myriad reasons, including the long acquisition time, problematic motion artifact, and inconsistent availability. More important than the pragmatic downsides, its sensitivity and specificity for aneurysm detection, particularly for aneurysms $\leq 5 \mathrm{~mm}$, is inferior to that of CTA and DSA. ${ }^{16}$ In rare instances, MRA is the preferred modality, such as when pregnancy is suspected and limiting the radiation dose is critically important.

Figures 5 and 6 show CT, CTA, DSA, and treatment images of 2 typical patients, one who underwent clipping and another who underwent coiling, respectively.

\section{Posttreatment Imaging}

Posttreatment surveillance imaging of intracranial aneurysms is determined by modality, local standard of care, and provider experience. No guidelines for follow-up imaging after treatment of intracranial aneurysms exist currently. This is in large part due to heterogeneity in imaging in combination with small numbers and the retrospective nature of published series on the side of microsurgical treatment..$^{10,19,57}$ For endovascularly treated aneurysms, 

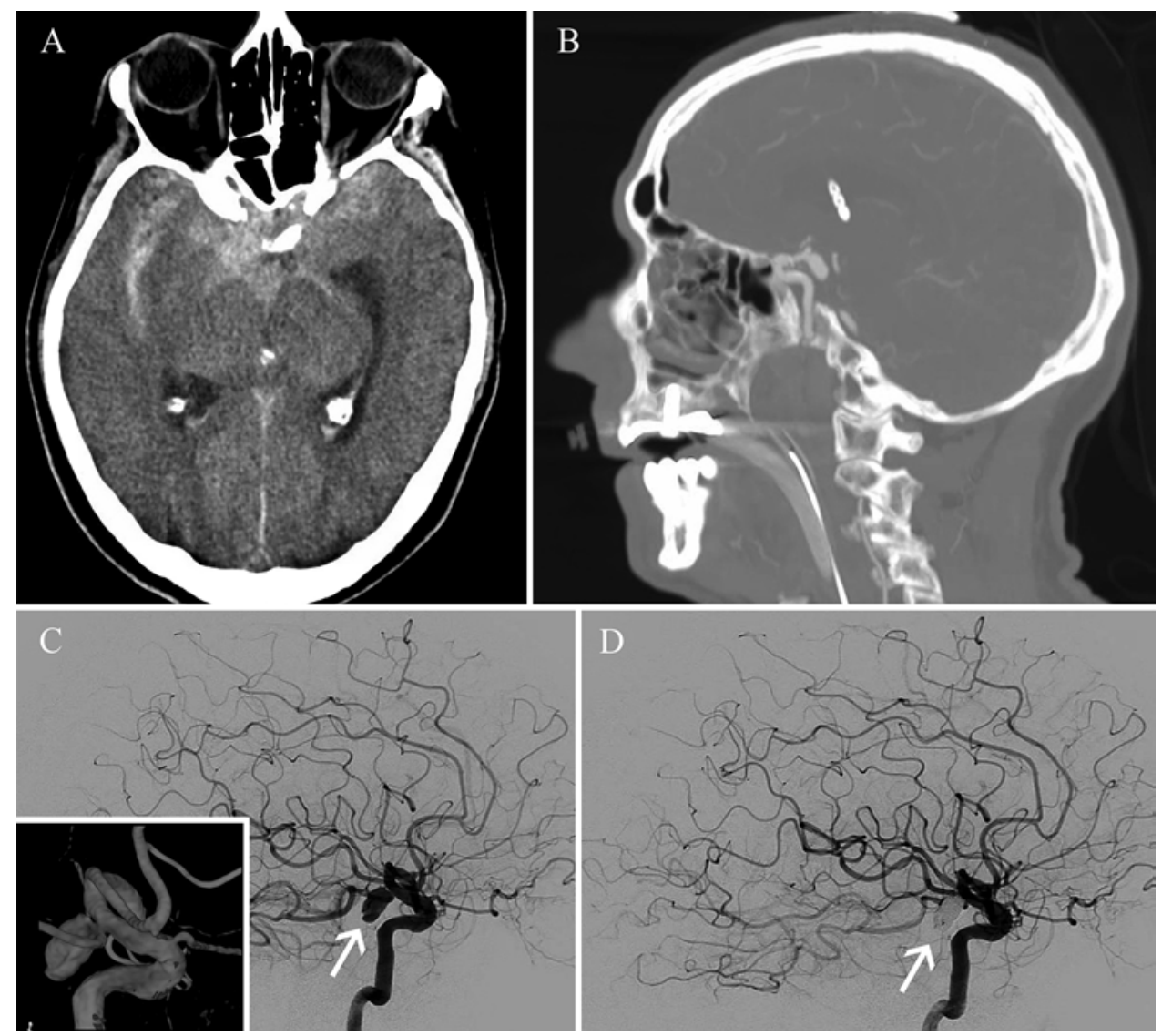

FIG. 6. Imaging examples typical of an SAH patient who underwent coiling. A: CT scan revealing the classic pattern of aneurysmal SAH. B: CTA image demonstrating a posterior communicating artery-origin ICA aneurysm. C: DSA better characterizes the aneurysm by 2D and 3D angiography (inset). D: Complete obliteration of the aneurysm with balloon-assisted coil embolization. The aneurysm is highlighted by the white arrow.

the variation in therapeutic technique from coiling, to balloon-assisted coiling, stent coiling, flow diversion, and now intrasaccular flow disruption, has hindered efforts to standardize posttreatment surveillance imaging. Further complicating recommendations regarding the timing and modality for follow-up imaging is the lack of a full understanding of the clinical significance of small recurrences at the aneurysm neck or the fate of purposefully "underclipped" or "undercoiled" aneurysms that would have led to a stroke through parent or branch vessel occlusion if a complete "radiographic cure" had been pursued. ${ }^{10,34,56}$

Microsurgical clipping of intracranial aneurysms, historically, has been thought to be extremely durable with low recurrence rates. Indeed, modern adjuncts to aneurysm clipping have resulted in better rates of complete aneurysm occlusion after clipping. Intraoperative angiography (IOA) is useful to assess parent vessel compromise and limit the risk of ischemic complications. In addition, IOA allows the surgeon to evaluate for residual aneurysm filling that would place the patient at risk of having a recurrent aneurysm. In a large series of patients, Tang et al. ${ }^{54}$ found that IOA resulted in a surgical change in $12.4 \%$ of cases, most commonly clip readjustment to completely occlude an aneurysm that continued to fill. Secondarily, clips were readjusted for parent or branch vessel compromise. Indocyanine green video angiography (ICGVA), in which an intravenous bolus of indocyanine green is given and then detected using a near-infrared filter on the operating microscope, has emerged as a useful tool in the surgical treatment of cerebrovascular disorders. While not a radiographic procedure, ICGVA is a useful addition to IOA, though not a replacement, as IOA provides superior temporal resolution, directionality of flow, and an image beyond the microsurgical field. The advantage of IGCVA is its speed as images can be obtained without any change to the operating room setup, and surgical changes can be implemented immediately as a result of ICGVA.41,47

Despite angiographic evidence of complete or nearcomplete occlusion intraoperatively, the rate of aneurysm recurrence after clipping might be higher than commonly thought. In the literature, the rate of recurrence for a completely clipped aneurysm is less than $1 \%$ per year, ${ }^{19,57}$ however, long-term series put the rate of recurrence as high as 5\% over a follow-up period approaching 10 years. ${ }^{10,19,57}$ While the rate of recurrence for completely clipped aneurysms is around $1 \%-2 \%$ across series, the rate of recurrence for clipped aneurysms with a known residual component is substantially higher. Known "dog-ear" residuals 
may enlarge in as many as $25 \%$ of cases, while broad-based residuals enlarge in as much as $75 \%$ of cases..$^{19}$ Moreover, the likelihood of discovering a de novo aneurysm on longterm follow-up angiography or CTA varies across series from approximately $3 \%$ to $10 \% .^{10,19,69}$ Taken together, these data suggest that follow-up imaging for clipped aneurysms should be pursued to rule out significant recurrence for aneurysms that have a known residual and to evaluate for de novo aneurysms, irrespective of how well the index aneurysm was clipped. While determined on a case-bycase basis, aneurysms with a known residual are imaged relatively early (within 1-2 years), while those that are completely clipped are imaged approximately 5-10 years postoperatively, primarily to evaluate for de novo aneurysm formation. In most instances, noninvasive imaging, such as CTA or MRA, is sufficient; however, for patients in whom retreatment may be considered, DSA is often the preferred modality.

The most frequently cited detractor for endovascular treatment of aneurysms is the high recurrence rate, which can be as high as $20 \%$ or more depending on the imaging modality. ${ }^{18}$ The timing of imaging follow-up for endovascularly treated aneurysms and the type of imaging employed varies somewhat by type of procedure. Data suggest that aneurysms that are completely occluded by endovascular techniques are unlikely to recur in a delayed fashion. In a large multicenter study, Ferns et al. ${ }^{22}$ showed that, of 400 patients with 440 aneurysms, 11 (2.5\%) recurred, 9 of which had previously ruptured. Multivariate analysis showed that bifurcation aneurysms and aneurysms larger than $10 \mathrm{~mm}$ were at a statistically higher risk of recurrence. Data are clear that aneurysms treated by coil embolization or stent-assisted coiling portend a significant recurrence rate if not completely obliterated, either at the time of coiling or on short-term follow-up.

These data, like those for clipping, suggest that, though the likelihood of recurrent aneurysmal SAH is low, incompletely treated aneurysms should be followed up over time both to evaluate the treated aneurysm and to evaluate for de novo aneurysm formation. No consensus exists regarding the modality or timing of imaging for followup of aneurysms treated with endovascular therapy. In part, this is because some have argued that, though the risk of aneurysm recurrence may be high, the fate of residual and "growing" neck remnants, for instance, is unclear, and routine long-term imaging is not cost-effective given the low rate of recurrent hemorrhage. ${ }^{62} \mathrm{DSA}$ is the imaging modality of choice for the short-term follow-up of endovascularly treated aneurysms. MRA of varying techniques has become routine in the late follow-up of intracranial aneurysms. TOF MRA is of sufficient resolution for most coiled aneurysms to detect the majority of clinically meaningful recurrences that would have been otherwise seen on DSA with a sensitivity and specificity above 90\%. ${ }^{18}$ TR CE-MRA, while only slightly better in terms of sensitivity and specificity relative to TOF MRA for coiling cases, is much better for detecting recurrent aneurysms when laser-cut stents or flow diverters have been used, as the increased surface area coverage of metal in the parent vessel leads to radiofrequency shielding and an obscured view when using TOF MRA.7,14
Most of the principles expounded upon regarding posttreatment surveillance imaging of unruptured aneurysms apply to ruptured aneurysms, but some differences specific to the nature of ruptured aneurysms are worth pointing out. As previously cited, the most frequent criticism of endovascular treatment of aneurysms is the high recurrence rate, which is reported to be as high as $20 \%$ or higher for elective management of unruptured aneurysms depending on the modality. ${ }^{18}$ While data suggest that UIAs that are completely occluded by endovascular techniques are unlikely to recur in a delayed fashion, complete obliteration of endovascularly treated aneurysms was $22 \%(5 / 23)$ in the 10-year follow-up of patients in the Barrow Ruptured Aneurysm Trial. ${ }^{52}$ While these data are likely affected by attrition, the rate of residual/recurrent aneurysm was quite high at previous iterations of analysis $(60 / 115$ [52\%] immediate, 26/58 [45\%] at 3 years, and 16/40 [40\%] at 6 years). ${ }^{51,53}$ Moreover, of the 809 patients allocated to endovascular therapy in the International Subarachnoid Hemorrhage Trial (also known as ISAT), 13 suffered a rehemorrhage from the target aneurysm between 1 and 9 years after initial treatment. Of those 13, 3 died within 30 days, and of the remaining 10, 7 were neurologically independent at the end of the follow-up period. ${ }^{37}$ As a result, for ruptured aneurysms treated endovascularly, we typically perform follow-up DSA at 6 months after treatment and, depending on the result, pursue either additional treatment, such as coiling or flow diversion, or microsurgical clip ligation if necessary. ${ }^{28}$ If the endovascularly treated aneurysm is completely or near completely occluded at the 6-month follow-up visit, we perform follow-up MRA or TR CE-MRA, depending on whether a stent was used at the time of initial coiling at 2 years after treatment. We then default to MRA between 5 and 10 years from the initial hemorrhage to evaluate for de novo aneurysm formation. Similarly, if an aneurysm is completely obliterated by clip ligation with documentation of complete obliteration on IOA, we defer follow-up to the 5- to 10-year surveillance MRA.

\section{ANSAH}

ANSAH, or SAH for which no underlying vascular abnormality is identified on initial imaging, including DSA, is relatively common and accounts for $15 \%-20 \%$ of patients with spontaneous SAH..$^{11,26,45}$ ANSAH may occur as a number of bleed patterns, including that typical for aneurysmal SAH involving the basilar cisterns and sylvian fissures, perimesencephalic hemorrhage characterized by blood within the crural, ambient and quadrigeminal cisterns, and cortical SAH, SAH at the foramen magnum, and it may be associated with intraventricular hemorrhage $e^{2,33,46}$ (Fig. 7). The etiology of ANSAH in the majority of cases is never uncovered, and the putative cause is hemorrhage from a subarachnoid or cortical vein. No standard imaging protocol exists regarding imaging modalities and timing to completely rule out a cryptogenic lesion that requires treatment; however, to do so is of utmost importance as the risk of recurrent hemorrhage is high if a treatable cause of the initial SAH is not identified and adequately treated. In contrast, patients in whom no etiology is identi- 

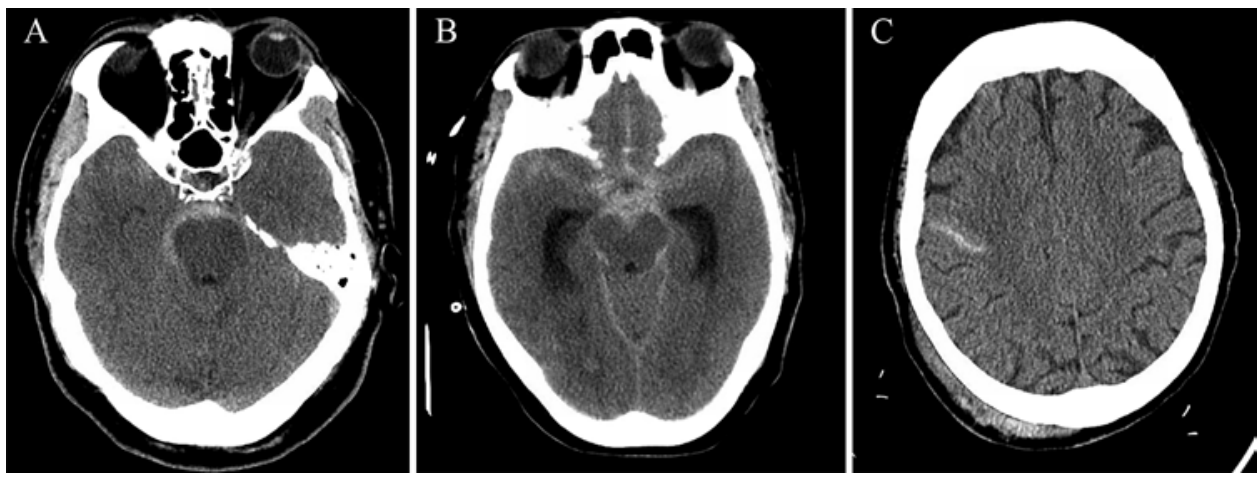

FIG. 7. Prototypical CT images of the predominant blood patterns seen in ANSAH, including perimesencephalic (A), classic aneurysmal (B), and cortical (C) patterns.

fied have an extremely low risk of a repeated SAH, and a thorough investigation that is ultimately negative often allays great anxiety. Possible causes of ANSAH are varied and include tiny or thrombosed aneurysms; hemorrhagic tumors; vascular or neoplastic lesions of the spine that include an intradural component; antiplatelet or anticoagulant medications; hypertension; and use of sympathomimetic drugs. ${ }^{33,46}$

Owing to the retrospective and limited nature of the available data, no consensus has been reached regarding the timing of imaging after the initial negative angiogram or which modalities are most appropriate. Little and colleagues ${ }^{33}$ published a series on 100 patients with ANSAH diagnosed on CT or by lumbar puncture (xanthochromia), 44 of whom presented with a classic aneurysm pattern,
16 with a perimesencephalic pattern, 25 at the convexity, and 15 diagnosed by lumbar puncture. A lesional etiology was subsequently discovered in $16 \%$ of patients in the aneurysm pattern group ( 6 aneurysms and 1 cervical neoplasm), whereas 1 aneurysm was discovered in the perimesencephalic group and a single case of vasculitis in the convexity group. The overall yield for a vascular or neoplastic etiology in the entire cohort was $9 \%$, with the most common cause being a previously unidentified aneurysm. A second angiogram during the initial hospitalization revealed 5 of 6 aneurysms. A third outpatient angiogram revealed the sixth aneurysm. The most common reasons for missed aneurysms were thrombosis, tiny size, distal location, or inadequate angiographic views without 3D reconstructions. Inpatient MRI demonstrated

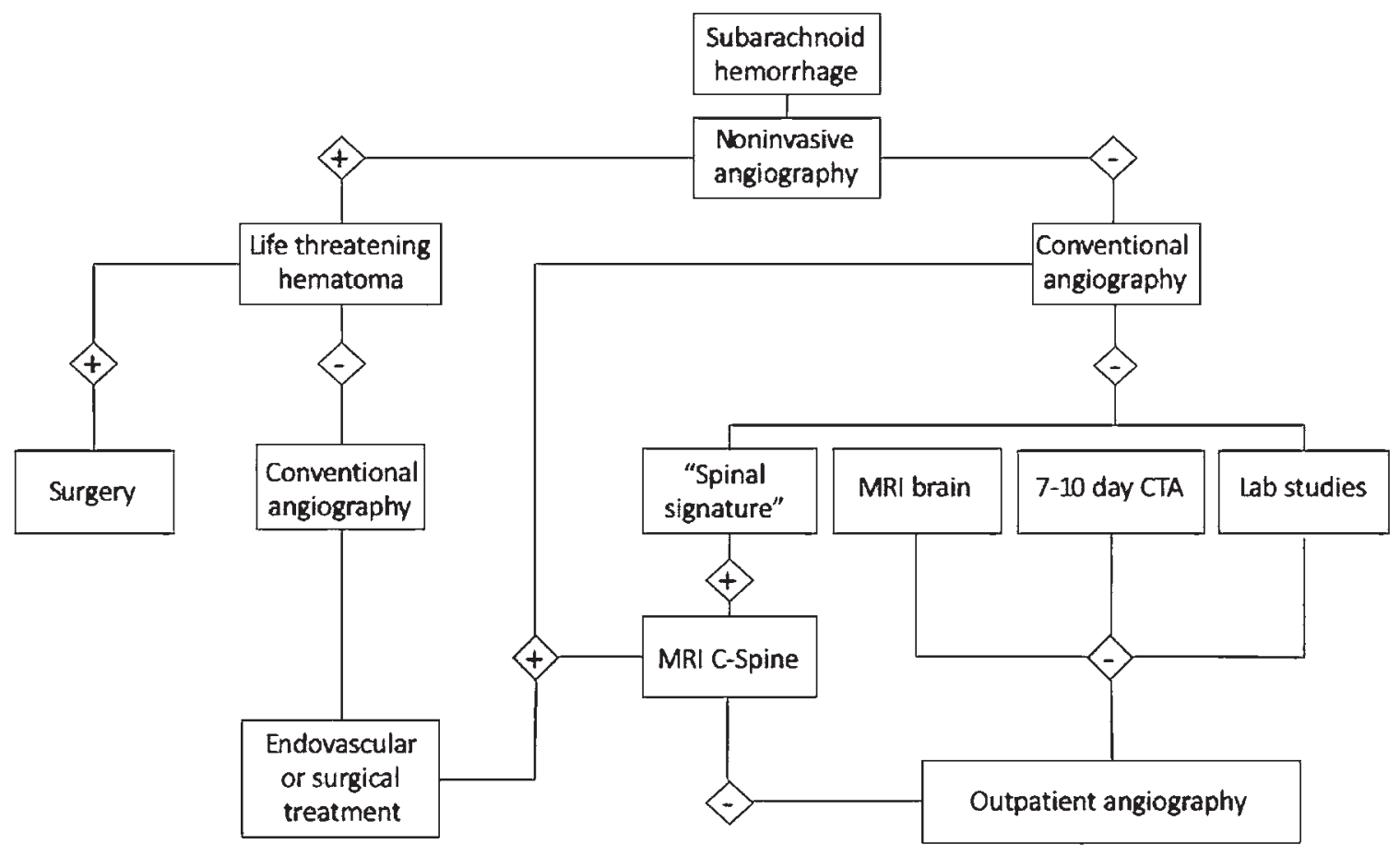

FIG. 8. Our institutional flowchart for the workup of ANSAH. C-Spine = cervical spine. 
a cervical neoplasm in a single patient, who presented with a classic pattern of SAH. Other series have found low rates of causative spinal pathology leading to ANSAH. ${ }^{26,48}$ In a series of nonaneurysmal, nonperimesencephalic SAH, Germans et al. ${ }^{26}$ discovered spinal pathology in 3 of 75 (4\%) patients, including 2 patients with cervical cavernous malformations and 1 with a lumbar ependymoma. In a large series of 240 patients with ANSAH, Sadigh et al. ${ }^{48}$ showed that cervical MRI uncovered a single spinal arteriovenous malformation as a cause of the hemorrhage. In a meta-analysis of 538 patients, the diagnostic yield of cervical MRI in the setting of ANSAH was $1.3 \%$. On the basis of these data, we do not routinely perform cervical axial imaging unless the patient has a spinal signature to their presentation. Patients with initial neck or back pain should raise the suspicion of a spinal etiology for the SAH. Our diagnostic algorithm for the workup of SAH is depicted in Fig. 8.

\section{Conclusions}

Imaging is essential for the diagnosis, surveillance, treatment, and posttreatment follow-up of intracranial aneurysms. DSA remains the gold-standard modality for imaging intracranial aneurysms due to its high spatial and temporal resolution, but it has the disadvantages of being invasive and expensive, while exposing the patient and healthcare staff to large doses of radiation. CTA and MRA are noninvasive and inexpensive relative to DSA, where CTA confers a lesser dose of radiation than a typical diagnostic angiogram and MRA does not utilize ionizing radiation. Of utmost importance for future research will be the development of imaging paradigms and standards that provide a high degree of diagnostic accuracy that informs treatment, both to prevent SAH and once SAH has occurred, but that both considers cost to the healthcare system and balances risk to the patient in terms of complications and anxiety.

\section{References}

1. Al-Khindi T, Macdonald RL, Schweizer TA: Cognitive and functional outcome after aneurysmal subarachnoid hemorrhage. Stroke 41:e519-e536, 2010

2. Andaluz N, Zuccarello M: Yield of further diagnostic workup of cryptogenic subarachnoid hemorrhage based on bleeding patterns on computed tomographic scans. Neurosurgery 62:1040-1047, 2008

3. Asaithambi G, Adil MM, Chaudhry SA, Qureshi AI: Incidences of unruptured intracranial aneurysms and subarachnoid hemorrhage: results of a statewide study. J Vasc Interv Neurol 7:14-17, 2014

4. Backes D, Rinkel GJ, Kemperman H, Linn FH, Vergouwen MD: Time-dependent test characteristics of head computed tomography in patients suspected of nontraumatic subarachnoid hemorrhage. Stroke 43:2115-2119, 2012

5. Bederson JB, Connolly ES Jr, Batjer HH, Dacey RG, Dion $\mathrm{JE}$, Diringer MN, et al: Guidelines for the management of aneurysmal subarachnoid hemorrhage: a statement for healthcare professionals from a special writing group of the Stroke Council, American Heart Association. Stroke 40:994-1025, 2009

6. Bender MT, Wendt H, Monarch T, Beaty N, Lin LM, Huang $\mathrm{J}$, et al: Small aneurysms account for the majority and increasing percentage of aneurysmal subarachnoid hemor- rhage: a 25-year, single institution study. Neurosurgery 83:692-699, 2018

7. Boddu SR, Tong FC, Dehkharghani S, Dion JE, Saindane AM: Contrast-enhanced time-resolved MRA for follow-up of intracranial aneurysms treated with the pipeline embolization device. AJNR Am J Neuroradiol 35:2112-2118, 2014

8. Bos D, Poels MM, Adams HH, Akoudad S, Cremers LG, Zonneveld HI, et al: Prevalence, clinical management, and natural course of incidental findings on brain MR images: the Population-based Rotterdam Scan Study. Radiology 281:507-515, 2016

9. Burkhardt JK, Chua MH, Winkler EA, Rutledge WC, Lawton MT: Incidence, classification, and treatment of angiographically occult intracranial aneurysms found during microsurgical aneurysm clipping of known aneurysms. J Neurosurg [epub ahead of print February 22, 2019; DOI: 10.3171/2018.11.JNS182416]

10. Burkhardt JK, Chua MHJ, Weiss M, Do ASS, Winkler EA, Lawton MT: Risk of aneurysm residual regrowth, recurrence, and de novo aneurysm formation after microsurgical clip occlusion based on follow-up with catheter angiography. World Neurosurg 106:74-84, 2017

11. Canneti B, Mosqueira AJ, Nombela F, Gilo F, Vivancos J: Spontaneous subarachnoid hemorrhage with negative angiography managed in a stroke unit: clinical and prognostic characteristics. J Stroke Cerebrovasc Dis 24:2484-2490, 2015

12. Carpenter CR, Hussain AM, Ward MJ, Zipfel GJ, Fowler S, Pines JM, et al: Spontaneous subarachnoid hemorrhage: a systematic review and meta-analysis describing the diagnostic accuracy of history, physical examination, imaging, and lumbar puncture with an exploration of test thresholds. Acad Emerg Med 23:963-1003, 2016

13. Chappell ET, Moure FC, Good MC: Comparison of computed tomographic angiography with digital subtraction angiography in the diagnosis of cerebral aneurysms: a metaanalysis. Neurosurgery 52:624-631, 2003

14. Choi JW, Roh HG, Moon WJ, Kim NR, Moon SG, Kang CH, et al: Time-resolved 3D contrast-enhanced MRA on 3.0T: a non-invasive follow-up technique after stent-assisted coil embolization of the intracranial aneurysm. Korean J Radiol 12:662-670, 2011

15. Cloft HJ, Joseph GJ, Dion JE: Risk of cerebral angiography in patients with subarachnoid hemorrhage, cerebral aneurysm, and arteriovenous malformation: a meta-analysis. Stroke 30:317-320, 1999

16. Connolly ES Jr, Rabinstein AA, Carhuapoma JR, Derdeyn CP, Dion J, Higashida RT, et al: Guidelines for the management of aneurysmal subarachnoid hemorrhage: a guideline for healthcare professionals from the American Heart Association/American Stroke Association. Stroke 43:1711-1737, 2012

17. Cornelissen BMW, Leemans EL, Coolen BF, Peper ES, van den Berg R, Marquering HA, et al: Insufficient slow-flow suppression mimicking aneurysm wall enhancement in magnetic resonance vessel wall imaging: a phantom study. Neurosurg Focus 47(1):E19, 2019

18. Crobeddu E, Lanzino G, Kallmes DF, Cloft HJ: Review of 2 decades of aneurysm-recurrence literature, part 2: Managing recurrence after endovascular coiling. AJNR Am J Neuroradiol 34:481-485, 2013

19. David CA, Vishteh AG, Spetzler RF, Lemole M, Lawton MT, Partovi S: Late angiographic follow-up review of surgically treated aneurysms. J Neurosurg 91:396-401, 1999

20. Edlow JA: Diagnosis of subarachnoid hemorrhage. Neurocrit Care 2:99-109, 2005

21. Feng TY, Han XF, Lang R, Wang F, Wu Q: Subtraction CT angiography for the detection of intracranial aneurysms: a meta-analysis. Exp Ther Med 11:1930-1936, 2016

22. Ferns SP, Sprengers ME, van Rooij WJ, van Zwam WH, de 
Kort GA, Velthuis BK, et al: Late reopening of adequately coiled intracranial aneurysms: frequency and risk factors in 400 patients with 440 aneurysms. Stroke 42:1331-1337, 2011

23. Fifi JT, Meyers PM, Lavine SD, Cox V, Silverberg L, Mangla $\mathrm{S}$, et al: Complications of modern diagnostic cerebral angiography in an academic medical center. J Vasc Interv Radiol 20:442-447, 2009

24. Fujii Y, Takeuchi S, Sasaki O, Minakawa T, Koike T, Tanaka R: Ultra-early rebleeding in spontaneous subarachnoid hemorrhage. J Neurosurg 84:35-42, 1996

25. Futami K, Sano H, Misaki K, Nakada M, Ueda F, Hamada J: Identification of the inflow zone of unruptured cerebral aneurysms: comparison of 4D flow MRI and 3D TOF MRA data. AJNR Am J Neuroradiol 35:1363-1370, 2014

26. Germans MR, Coert BA, Majoie CB, van den Berg R, Lycklama À Nijeholt G, Rinkel GJ, et al: Yield of spinal imaging in nonaneurysmal, nonperimesencephalic subarachnoid hemorrhage. Neurology 84:1337-1340, 2015

27. Gonzalez LF, Walker MT, Zabramski JM, Partovi S, Wallace RC, Spetzler RF: Distinction between paraclinoid and cavernous sinus aneurysms with computed tomographic angiography. Neurosurgery 52:1131-1139, 2003

28. Howard BM, Frerich JM, Madaelil TP, Dion JE, Tong FC, Cawley CM, et al: 'Plug and pipe' strategy for treatment of ruptured intracranial aneurysms. J Neurointerv Surg 11:43-48, 2019

29. Kassell NF, Kongable GL, Torner JC, Adams HP Jr, Mazuz $\mathrm{H}$ : Delay in referral of patients with ruptured aneurysms to neurosurgical attention. Stroke 16:587-590, 1985

30. Kaufmann TJ, Huston J III, Cloft HJ, Mandrekar J, Gray $\mathrm{L}$, Bernstein MA, et al: A prospective trial of 3T and 1.5T time-of-flight and contrast-enhanced MR angiography in the follow-up of coiled intracranial aneurysms. AJNR Am J Neuroradiol 31:912-918, 2010

31. Kowalski RG, Claassen J, Kreiter KT, Bates JE, Ostapkovich $\mathrm{ND}$, Connolly ES, et al: Initial misdiagnosis and outcome after subarachnoid hemorrhage. JAMA 291:866-869, 2004

32. Leffers AM, Wagner A: Neurologic complications of cerebral angiography. A retrospective study of complication rate and patient risk factors. Acta Radiol 41:204-210, 2000

33. Little AS, Garrett M, Germain R, Farhataziz N, Albuquerque FC, McDougall CG, et al: Evaluation of patients with spontaneous subarachnoid hemorrhage and negative angiography. Neurosurgery 61:1139-1151, 2007

34. Madaelil TP, Grossberg JA, Howard BM, Cawley CM, Dion J, Nogueira RG, et al: Aneurysm remnants after flow diversion: clinical and angiographic outcomes. AJNR Am J Neuroradiol 40:694-698, 2019

35. Mayberg MR: Warning leaks and subarachnoid hemorrhage. West J Med 153:549-550, 1990

36. Menke J, Larsen J, Kallenberg K: Diagnosing cerebral aneurysms by computed tomographic angiography: meta-analysis. Ann Neurol 69:646-654, 2011

37. Molyneux AJ, Birks J, Clarke A, Sneade M, Kerr RS: The durability of endovascular coiling versus neurosurgical clipping of ruptured cerebral aneurysms: 18 year follow-up of the UK cohort of the International Subarachnoid Aneurysm Trial (ISAT). Lancet 385:691-697, 2015

38. Morita A, Kirino T, Hashi K, Aoki N, Fukuhara S, Hashimoto $\mathrm{N}$, et al: The natural course of unruptured cerebral aneurysms in a Japanese cohort. N Engl J Med 366:2474-2482, 2012

39. Naidech AM, Janjua N, Kreiter KT, Ostapkovich ND, Fitzsimmons BF, Parra A, et al: Predictors and impact of aneurysm rebleeding after subarachnoid hemorrhage. Arch Neurol 62:410-416, 2005

40. Naval NS, Chang T, Caserta F, Kowalski RG, Carhuapoma JR, Tamargo RJ: Impact of pattern of admission on outcomes after aneurysmal subarachnoid hemorrhage. J Crit Care 27:532.e1-532.e7, 2012
41. Norat P, Soldozy S, Elsarrag M, Sokolowski J, Yağmurlu K, Park MS, et al: Application of indocyanine green videoangiography in aneurysm surgery: evidence, techniques, practical tips. Front Surg 6:34, 2019

42. Ogden JA, Utley T, Mee EW: Neurological and psychosocial outcome 4 to 7 years after subarachnoid hemorrhage. Neurosurgery 41:25-34, 1997

43. Pradilla G, Wicks RT, Hadelsberg U, Gailloud P, Coon AL, Huang J, et al: Accuracy of computed tomography angiography in the diagnosis of intracranial aneurysms. World Neurosurg 80:845-852, 2013

44. Rinkel GJ, Djibuti M, Algra A, van Gijn J: Prevalence and risk of rupture of intracranial aneurysms: a systematic review. Stroke 29:251-256, 1998

45. Rinkel GJ, Wijdicks EF, Hasan D, Kienstra GE, Franke CL, Hageman LM, et al: Outcome in patients with subarachnoid haemorrhage and negative angiography according to pattern of haemorrhage on computed tomography. Lancet 338:964968, 1991

46. Rinkel GJ, Wijdicks EF, Vermeulen M, Ramos LM, Tanghe HL, Hasan D, et al: Nonaneurysmal perimesencephalic subarachnoid hemorrhage: CT and MR patterns that differ from aneurysmal rupture. AJNR Am J Neuroradiol 12:829-834, 1991

47. Roessler K, Krawagna M, Dörfler A, Buchfelder M, Ganslandt O: Essentials in intraoperative indocyanine green videoangiography assessment for intracranial aneurysm surgery: conclusions from 295 consecutively clipped aneurysms and review of the literature. Neurosurg Focus 36(2):E7, 2014

48. Sadigh G, Holder CA, Switchenko JM, Dehkharghani S, Allen JW: Is there added value in obtaining cervical spine MRI in the assessment of nontraumatic angiographically negative subarachnoid hemorrhage? A retrospective study and metaanalysis of the literature. J Neurosurg 129:670-676, 2018

49. Sailer AM, Wagemans BA, Nelemans PJ, de Graaf R, van Zwam WH: Diagnosing intracranial aneurysms with MR angiography: systematic review and meta-analysis. Stroke 45:119-126, 2014

50. Shah KH, Richard KM, Nicholas S, Edlow JA: Incidence of traumatic lumbar puncture. Acad Emerg Med 10:151-154, 2003

51. Spetzler RF, McDougall CG, Albuquerque FC, Zabramski JM, Hills NK, Partovi S, et al: The Barrow Ruptured Aneurysm Trial: 3-year results. J Neurosurg 119:146-157, 2013

52. Spetzler RF, McDougall CG, Zabramski JM, Albuquerque FC, Hills NK, Nakaji P, et al: Ten-year analysis of saccular aneurysms in the Barrow Ruptured Aneurysm Trial. J Neurosurg [epub ahead of print March 8, 2019; DOI: 10.3171/2018.8.JNS181846]

53. Spetzler RF, McDougall CG, Zabramski JM, Albuquerque FC, Hills NK, Russin JJ, et al: The Barrow Ruptured Aneurysm Trial: 6-year results. J Neurosurg 123:609-617, 2015

54. Tang G, Cawley CM, Dion JE, Barrow DL: Intraoperative angiography during aneurysm surgery: a prospective evaluation of efficacy. J Neurosurg 96:993-999, 2002

55. Thines L, Gauvrit JY, Leclerc X, Le Gars D, Delmaire C, Pruvo JP, et al: Usefulness of MR imaging for the assessment of nonophthalmic paraclinoid aneurysms. AJNR Am J Neuroradiol 29:125-129, 2008

56. Thornton J, Bashir Q, Aletich VA, Debrun GM, Ausman JI, Charbel FT: What percentage of surgically clipped intracranial aneurysms have residual necks? Neurosurgery 46:1294-1300, 2000

57. Tsutsumi K, Ueki K, Morita A, Usui M, Kirino T: Risk of aneurysm recurrence in patients with clipped cerebral aneurysms: results of long-term follow-up angiography. Stroke 32:1191-1194, 2001

58. Turan N, Heider RA, Roy AK, Miller BA, Mullins ME, Barrow DL, et al: Current perspectives in imaging modalities for 
the assessment of unruptured intracranial aneurysms: a comparative analysis and review. World Neurosurg 113:280292,2018

59. van Gijn J, Rinkel GJ: Subarachnoid haemorrhage: diagnosis, causes and management. Brain 124:249-278, 2001

60. Warnock NG, Gandhi MR, Bergvall U, Powell T: Complications of intraarterial digital subtraction angiography in patients investigated for cerebral vascular disease. Br J Radiol 66:855-858, 1993

61. Waugh JR, Sacharias N: Arteriographic complications in the DSA era. Radiology 182:243-246, 1992

62. Wermer MJH, Koffijberg H, van der Schaaf IC: Effectiveness and costs of screening for aneurysms every 5 years after subarachnoid hemorrhage. Neurology 70:2053-2062, 2008

63. Wermer MJH, van Walderveen MAA, Garpebring A, van Osch MJP, Versluis MJ: 7 Tesla MRA for the differentiation between intracranial aneurysms and infundibula. Magn Reson Imaging 37:16-20, 2017

64. Westerlaan HE, van Dijk JM, Jansen-van der Weide MC, de Groot JC, Groen RJ, Mooij JJ, et al: Intracranial aneurysms in patients with subarachnoid hemorrhage: CT angiography as a primary examination tool for diagnosis - systematic review and meta-analysis. Radiology 258:134-145, 2011 (Erratum in Radiology 260:612, 2011)

65. White PM, Wardlaw JM, Easton V: Can noninvasive imaging accurately depict intracranial aneurysms? A systematic review. Radiology 217:361-370, 2000

66. White PM, Wardlaw JM, Lindsay KW, Sloss S, Patel DK, Teasdale EM: The non-invasive detection of intracranial aneurysms: are neuroradiologists any better than other observers? Eur Radiol 13:389-396, 2003

67. Wiebers DO, Whisnant JP, Huston J III, Meissner I, Brown RD Jr, Piepgras DG, et al: Unruptured intracranial aneurysms: natural history, clinical outcome, and risks of surgical and endovascular treatment. Lancet 362:103-110, 2003
68. Yanamadala V, Sheth SA, Walcott BP, Buchbinder BR, Buckley D, Ogilvy CS: Non-contrast 3D time-of-flight magnetic resonance angiography for visualization of intracranial aneurysms in patients with absolute contraindications to $\mathrm{CT}$ or MRI contrast. J Clin Neurosci 20:1122-1126, 2013

69. Zali A, Khoshnood RJ, Zarghi A: De novo aneurysms in long-term follow-up computed tomographic angiography of patients with clipped intracranial aneurysms. World Neurosurg 82:722-725, 2014

70. Zhang LJ, Wu SY, Niu JB, Zhang ZL, Wang HZ, Zhao YE, et al: Dual-energy CT angiography in the evaluation of intracranial aneurysms: image quality, radiation dose, and comparison with 3D rotational digital subtraction angiography. AJR Am J Roentgenol 194:23-30, 2010

\section{Disclosures}

Dr. Hu reports receiving an honorarium from Siemens for speaking at a Siemens Dual Energy Workshop.

\section{Author Contributions}

Conception and design: all authors. Acquisition of data: all authors. Drafting the article: all authors. Critically revising the article: all authors. Reviewed submitted version of manuscript: Howard, Hu, DL Barrow. Approved the final version of the manuscript on behalf of all authors: Howard.

\section{Correspondence}

Brian M. Howard: Emory University School of Medicine, Atlanta, GA.brian.howard@emory.edu. 